\title{
A TAXONOMIA DE BLOOM APLICADA NA AVALIAÇÃO EM DIREITO
}

\author{
Ricardo Gabriel de Araújo, Danielle Aparecida Nascimento Santos
}

Universidade do Oeste Paulista - UNOESTE, Pós Graduação "Latu Sensu” Avaliação do Ensino e Aprendizado, NEAD Núcleo de Ensino a Distância, Presidente Prudente, SP. E-mail: ricardoaraujo@unoeste.br

\section{RESUMO}

O presente estudo apresentará métodos de utilização da taxonomia de Bloom aliado a didática participativa do docente no curso de Direito. O objetivo deste estudo é ofertar ao leitor uma ótica sobre o processo avaliativo no Ensino Superior na área do Direito, oferecendo uma forma de avaliação baseada em respostas com diferentes graus de complexidade, melhorando a prática e raciocínio jurídico dos discentes do curso de Direito focando em uma avaliação com questões de baixa, média e alta complexidade pelo uso da taxonomia de Bloom. Com essa metodologia o aluno apresentará respostas de acordo com o grau de complexidade das questões previamente elaboradas atingindo de tal modo o resultado esperado.Concluímos que aliado com a Didática Participativa a Taxonomia de Bloom resultará em um melhor amadurecimento intelectual de cada estudante apontando melhores resultados em processos avaliativos, formando um profissional mais crítico com ampla capacidade de analítica sem perder a formação humana.

Palavras-chave: Avaliação. Taxonomia. Bloom. Direito. Didática.

\section{THE BLOOM 'S TAXONOMY APPLIED IN THE AVALIATION IN LAW COURSE}

\begin{abstract}
This study will present methods of use of Bloom's taxonomy combined with participatory of teachers teaching in the course of law. The aim of this study is to offer the reader a perspective on the evaluation process in higher education in the area of law, providing a form of assessment based on responses with different degrees of complexity, improving the practical and legal reasoning of the law school's students focusing on An assessment issues low, medium and high complexity when using Bloom's taxonomy. With this method the student will submit responses according to the degree of complexity of the issues affecting previously developed in such a way that the result esperado.Concluímos allied with the Participatory Teaching Bloom's Taxonomy result in better intellectual maturity of each student pointing better results evaluation processes, forming a more critical professional with extensive analytical capabilities without losing the human formation.
\end{abstract}

Keywords: Avaliation. Taxonomy. Bloom . Law. Didactics. 


\section{INTRODUÇÃO}

O tema aqui tratado visa demonstrar de forma clara e precisa que os alunos apresentam um melhor envolvimento com o conteúdo quando da utilização de recursos didáticos que insira os mesmos em uma realidade mais próxima com o conteúdo estudado em sala de aula.

A utilização de uma Didática Participativa do Professor aliada com o uso da Taxonomia de Bloom resulta em um melhor amadurecimento intelectual de cada discente ao longo de sua trajetória acadêmica, apontando melhores resultados em processos avaliativos futuros.

O emprego da Taxonomia ligada com a didática participativa fará com que o que o aluno apresente respostas de acordo com o grau de complexidade das questões previamente elaboradas pelo docente avaliador, ou seja, a aplicação de comandos verbais específicos fará com que o aluno utilize um grau de conhecimento de acordo com a complexidade das questões, atingindo de tal modo o resultado esperado, rompendo o pensamento de ingressante de que é indispensável a memorização de artigos de lei.

A utilização de comandos verbais permite avaliar os seguintes processos: conhecimento, compreensão, aplicação, análise, síntese e avaliação, fazendo com que o aluno passe por todas essas etapas alcançando o resultado esperado, qual seja, a formação de um profissional crítico reflexivo, não sendo um mero repetidor de ideias.

Assim, o trabalho irá apresentar em seu corpo como deverá o Professor avaliador realizar a inserção da taxonomia de Bloom em suas avaliações, não deixando de aliar o uso deste recurso com a didática mais participativa e o uso de exemplos práticos participativos.

Os exemplos práticos deverão ser aplicados aos alunos fazendo uma ligação entre os problemas apresentados em casos reais, assim como os noticiados em principais meios de comunicação, tais como televisão, internet, jornais e revistas.

A apresentação do problema de repercussão midiática trará ao professor uma melhor facilidade de apresentar o tema proposto mostrando ao discente a correta aplicação da norma, lei, decreto e legislação específica.

Utilizando-se destes recursos o trabalho apresentará seu principal objetivo que é o de mostrar a importância do uso da Taxonomia de Bloom no curso de Direito para formação de alunos com ampliada capacidade de análise e crítica sobre qualquer assunto jurídico, não sendo um mero repetidor de ideias.

Ao longo do artigo, abordaremos o processo de aprendizagem, para entendermos como o estudante recebe a informação, processa e cria links com suas experiências anteriores de aprendizado. 
Destaca-se ainda o papel da memória na aprendizagem, que nos mostra a importância de uma boa memorização, não como uma fonte de retenção de conteúdo temporário, mas sim uma forma de aprendizado que ficará registrado na memória de cada indivíduo.

Outros pontos elementares abordados são a Didática e a Avaliação no Ensino Superior, assim como as abordagens de ensino na avaliação da aprendizagem.

Antes de introduzirmos o método sugerido de aplicação da taxonomia de Bloom no curso de Direito, será indispensável a abordagem do contrato didático a ser entabulado entre alunos e professores no primeiro encontro, ou seja, na aula inaugural, logo após o entendimento sobre a taxonomia de Bloom e curso de direito culminando na conclusão sobre o uso da taxonomia no curso de Direito.

\section{AVALIAÇÃO NO ENSINO SUPERIOR}

De acordo com Vasconcellos (2000), a avaliação é um processo abrangente da existência humana, que implica uma reflexão crítica sobre a prática, no sentido de captar seus avanços, suas resistências, suas dificuldades e possibilitar uma tomada de decisão sobre o que fazer para superar os problemas identificados / obstáculos.

De acordo com Luckesi (1999), a avaliação que se pratica na escola é a avaliação da culpa, e que as notas são usadas para fundamentar necessidades de classificação de alunos, onde são comparados desempenhos e não objetivos que se deseja atingir.

Segundo Lüdke; André, M. (1986),O universo da avaliação escolar é simbólico e instituído pela cultura da mensuração, legitimado pela linguagem jurídica dos regimentos escolares, que legalmente instituídos, funcionam como uma vasta rede e envolvem totalmente a escola.

A função nuclear da avaliação é ajudar o aluno a aprender e ao professor, ensinar. Perrenoud (1999), determinando também quanto e em que nível os objetivos estão sendo atingidos. Para isso é necessário o uso de instrumentos e procedimentos de avaliação adequados. Libâneo, (1994).

No entender de Luckesi (1999) "para não ser autoritária e conservadora, a avaliação tem a tarefa de ser diagnóstica, ou seja, deverá ser o instrumento dialético do avanço, terá de ser o instrumento da identificação de novos rumos". A avaliação deverá, para o autor, verificar a aprendizagem não só a partir dos mínimos possíveis, mas a partir dos mínimos necessário. Enfatiza também a importância dos critérios, pois a avaliação não poderá ser praticada sob dados inventados pelo professor, apesar da definição desses critérios não serem fixos e imutáveis, modificando-se de acordo com a necessidade de alunos e professores. 
Os médicos, engenheiros, arquitetos, advogados, administradores, odontólogos, veterinários, agrônomos, etc. que assumem a profissão de professores universitários estão, nesse contexto e em função de uma ausência de formação específica, pouco preparados para lidar com as questões pedagógico-didáticas, conforme o entendimento de Benedito e outros (1995), Vasconcelos (2000), Machado (1996) Cunha (1998), Ludke (1998).

Em decorrência disso, grande parte deles avalia da forma como foram avaliados em sua trajetória escolar, ou vão criando, a partir da experiência e do bom senso, maneiras de se avaliar o desempenho dos alunos. A maioria dos professores pratica uma avaliação tradicional, basicamente utilizando provas escritas para verificar a retenção dos conhecimentos repassados, não servindo para orientar ou reorientar o aluno, para situá-lo frente as exigências da disciplina e do curso e do papel que os conteúdos de cada disciplina tem na sua formação profissional. Em pesquisa realizada com professores e alunos de diferentes cursos, na UFPel, Cunha (1998, p. 32) aponta:

A questão da avaliação é a mais complexa e pode estar a revelar uma certa incompreensão dos objetivos da proposta (inovadora) por parte dos alunos e/ou uma certa indefinição quanto à forma e ao modo de avaliar numa proposta diferente por parte do professor. Ambos os sentimentos são próprios à construção do novo.

\section{AS ABORDAGENS DE ENSINO NA AVALIAÇÃO DA APRENDIZAGEM}

A avaliação nada mais é do que uma parte integrante de um processo de ensino, devendo o professor avaliador observar diversos elementos no transcorrer de dado período para observar os rendimentos e crescimento do avaliado.

Assim, torna-se indispensáveis a observação de duas abordagens específicas de aprendizagem, a condutivista e a construtivista.

O papel docente na abordagem condutivista é fornecer todas as informações necessárias para que o discente possa retê-las e aplica-las, possuindo os recursos didáticos função primordial, devendo esses serem estruturados em uma sequencia determinada com objetivos gerais, específicos e operacionais.

$\mathrm{Na}$ abordagem Construtivista, a realidade está mais na mente do conhecedor sendo ele quem constrói ou interpreta a situação com base em seus conhecimentos e experiências.

Ressalta-se ainda que sempre a melhor forma de avaliar um aluno não é somente ao final de um semestre ou somente em um único período, mas sim durante todo o período em que estiver na qualidade de aluno, podendo desta forma o avaliador acompanhar o desenvolvimento cognitivo de cada indivíduo. 
Assim, poderá ser realizada uma avaliação mais abrangente não havendo uma aplicação dicotômica de aprovar ou reprovar, mas sim avaliar o quanto o estudante evoluiu em determinado lapso temporal.

\section{O CONTRATO DIDÁTICO}

No primeiro contato havido entre aluno e professor deverá ser firmado entre as partes envolvidas um contrato, onde cada um saberá sua participação, assim como seus direitos e deveres quanto ao contratado.

O Prof. Mestre Edimarcio Testa em sua obra: Contrato didático: a relação de alunoprofessor-aluno no ensino superior, nos traz a seguinte conclusão de Chevarllad, quanto o contrato didático:

(...) o contrato reúne (criando como tal) três termos (três instâncias) e não duas como se acredita algumas vezes. $O$ aluno (o sujeito a quem se ensina), o professor (o sujeito que ensina) e o saber, considerado o "saber ensinado". 0 contrato rege, portanto a interação didática entre professor e alunos a propósito do saber - isto é o que chamo de relação "professor -aluno"... as cláusulas do contrato organizam as relações que os alunos e professores mantêm com saber. O Contrato rege até os detalhes do processo. Cada noção ensinada, cada tarefa proposta está submetida à sua legislação.

Assim, mostra-se essencial a formalização em primeiro contato entre professor-aluno de um contrato didático para um melhor aproveitamento de conteúdo, sendo o próximo passo a utilização de uma didática participativa e uso de taxonomia de Bloom em questionamentos e problematizações apresentadas em sala de aula, objetivando a formação de um profissional preparado para o mercado a que se destina, pensador e crítico.

\section{TAXONOMIA DE BLOOM}

Segundo a base Scielo, a Taxonomia de Bloom do Domínio Cognitivo é estruturada em níveis de complexidade crescente do mais simples ao mais complexo isso significa que, para adquirir uma nova habilidade pertencente ao próximo nível, o aluno deve ter dominado e adquirido a habilidade do nível anterior.

Diante deste entendimento, utilizando-se da Taxonomia, o professor avaliador, poderá elaborar questões de Baixa, média e alta complexidade, atingindo de tal modo os interesses a que pretende alcançar, a exemplo de mera apreciação do aluno quanto ao tema proposto, como a avaliação, apreciação, interpretação e crítica sobre o assunto abordado e ou problema apresentado. 
Analisamos os objetivos da Taxonomia de acordo com o seguinte padrão:

Conhecimento - Refere-se à habilidade do Aluno / Formando em recordar, definir, reconhecer ou identificar informação específica, a partir de situações de aprendizagem anteriores;

Compreensão - Refere-se à habilidade do Aluno / Formando em demonstrar compreensão pela informação, sendo capaz de reproduzir a mesma por ideias e palavras próprias;

Aplicação - Refere-se à habilidade do Aluno / Formando em recolher e aplicar informação em situações ou problemas concretos;

Análise - Refere-se à habilidade do Aluno / Formando em estruturar informação, separando as partes das matérias de aprendizagem e estabelecer relações, explicando-as, entre as partes constituintes;

Síntese - Refere-se à habilidade do Aluno / Formando em recolher e relacionar informação de várias fontes, formando um produto novo;

Avaliação - Refere-se à habilidade do Aluno / Formando em fazer julgamentos sobre o valor de algo (produtos, ideias, etc.) tendo em consideração critérios conhecidos.

A utilização de comandos verbais para cada momento apontará o que o professor deseja receber como resposta, fazendo com que o aluno torne-se um indivíduo mais crítico e avaliativo, ou seja, fará com que o estudante desenvolva cada vez mais sua capacidade de interpretação, análise, síntese e conclusão.

Em tempos atuais tornou-se quase que automático as primeiras indagações dos alunos para com os professores em seu primeiro contato, assim, na aula inaugural o discente sempre indaga o docente sobre o método, conteúdo e forma de avaliação, perguntando o seguinte: "o que cai na prova?", "teremos seminários?" "Quanto pontos valerá cada trabalho?".

Assim, utilizando-se dos métodos acima declinados, o professor em seu primeiro encontro com seus alunos, sejam novos ou anfitriões, efetuará a apresentação de todo o plano de aula, apresentando objetivos, conteúdo, formas de avaliação, seminários e demonstrará o que pretende com cada tópico apresentado, deixando bem claro para o alunos o que realmente será solicitado ao longo do período em que juntos estiverem ampliando conhecimentos.

A Taxonomia de Bloom representa neste plano um forte aliado para o desenvolvimento intelectual dos estudantes do curso de Direito, ou seja, a cada período (semestres, ano) em que se transcorrer o aluno vai alimentando a cada etapa os conhecimentos adquiridos e conseguindo ao longo do tempo desenvolver atividades que sejam interligadas entre si. 
Por exemplo, nos primeiros anos, o estudante estará recebendo conhecimentos gerais, como filosofia, sociologia, introdução ao estudo do direito, dentre outras elementares que servirão de base para a profissão a ser exercida, seja advogado, juiz, delegado de polícia ou um estudioso da ciência social jurídica.

Ressalta-se neste ponto que, desde o primeiro contato com os bancos universitários, o aluno deverá ser imerso na taxonomia de Bloom, tendo em vista que as disciplinas cursadas no inicio do curso são indispensáveis para o bom desenvolvimento intelectual e base filosófica social de cada profissional.

Se utilizada a taxonomia de baixa, média e alta complexidade nos alunos ingressantes do curso de direito, estará o professor contribuindo para uma formação mais completa, com discentes que começam a amadurecer seu conhecimento jurídico a partir da compreensão de temas anteriores, ou seja, não vão deixar o que foi discutido em sala de aula cair no esquecimento, tendo em vista que compreenderam o conteúdo aplicado e perceberam o motivo de sua abordagem, assim, quando entendido ficará registrado no conhecimento do aluno.

\section{CONCLUSÃO}

Analisando todo o assunto acima declinado, observamos que o processo de aprendizagem vem evoluindo a cada dia, ou seja, a cada dia aprendemos uma nova coisa que justifica ou complementa o último conhecimento adquirido.

Ao efetuar a aplicação da Taxonomia de Bloom no Curso de Direito, estará o docente utilizando-se de um recurso que irá fazer com que o aluno cada vez mais busque em sua mente estas caixas com as informações arquivadas, sendo o seu constante uso parte indispensáveis de uma técnica de aprendizado que irá fazer com o discente esteja sempre em contato com o conteúdo já estudo com aquele que está aprendendo no dia de hoje.

Assim, concluímos que o uso da taxonomia e Bloom no Curso de Direito torna-se uma técnica de extrema importância, não somente para a avaliação dos conhecimentos adquiridos pelo aluno, conseguindo mensurar o grau de complexidade do discente com o conteúdo estudado, mas como uma importante ferramenta na formação do futuro profissional que será inserido no mercado de trabalho, sendo um profissional com ampla capacidade de raciocínio, interpretação, demonstrando sua ampla compreensão sobre a leitura e acima de tudo, um domínio sobre o conteúdo de sua atuação, sendo um exímio formador de opinião.

\section{REFERÊNCIAS}

BORDENAVE, J. D.; PEREIRA, A. M. Estratégias de ensino-aprendizagem. Petrópolis: Vozes, 1983 
https://pt.wikipedia.org/wiki/Aprendizagem\#O_processo_de_aprendizagem_na_abordagem_de_ Vygotsky

http://www.infoescola.com/pedagogia/teoria-de-aprendizagem-de-piaget/

http://www.infoescola.com/pedagogia/teoria-de-aprendizagem-de-vygotsky/

http://www.infoescola.com/pedagogia/teoria-de-aprendizagem-de-skinner/

http://www.uneb.br/salvador/dedc/files/2011/05/Monografia-Jenifer-Satie-Vaz-Ogasawara.pdf

http://www.scielo.br/pdf/gp/v17n2/a15v17n2.pdf

MOREIRA, Marco Antônio. Teorias de Aprendizagens. São Paulo: EPU, 1995.

O Cérebro e as suas incríveis potencialidades: http://cerebro.weebly.com/aprendizagem.html

OLIVEIRA, Fabio dos Anjos, SANTOS, Cirlene Rodrigues dos, TESTA, Edmarcio. Contrato Didático: Relação de Aluno-Professor-Aluno no Ensino Superior. Revista Científica do ITPAC. V.1, no.1. 2008

PERRONOUD, Philippe. 10 novas competências para ensinar. Editora: Artmed, 2000

SILVA, Elcio Oliveira da, MOREIRA, Mariano e GRANDO, Neiva Ignês. O Contrato Didático e o currículo Oculto: Um Duplo Olhar obre o Fazer Pedagógico. Revista Zetetiké. V.4, no. 6. Campinas, 1996 